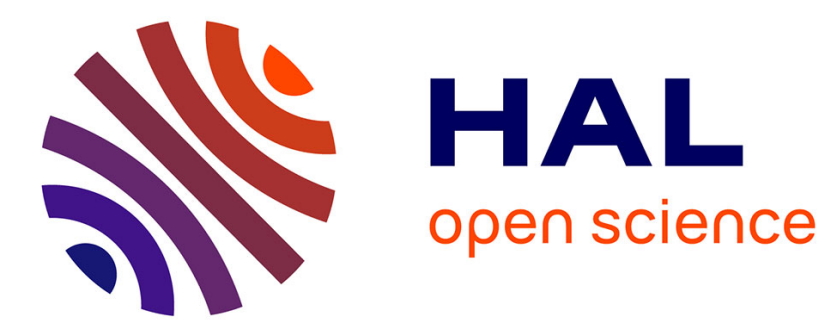

\title{
Ethyl Silicate for Unbaked Earth Tablets Conservation: Evaluation of the Physico-mechanical Aspects
} Mathilde Tiennot, Jean-Didier Mertz, Ann Bourges, Anne Liégey, Atika Chemmi, Anne Bouquillon

\section{- To cite this version:}

Mathilde Tiennot, Jean-Didier Mertz, Ann Bourges, Anne Liégey, Atika Chemmi, et al.. Ethyl Silicate for Unbaked Earth Tablets Conservation: Evaluation of the Physico-mechanical Aspects. Studies in Conservation, 2020, 10.1080/00393630.2020.1715057 . hal-02569418

\section{HAL Id: hal-02569418 https://hal.science/hal-02569418}

Submitted on 11 May 2020

HAL is a multi-disciplinary open access archive for the deposit and dissemination of scientific research documents, whether they are published or not. The documents may come from teaching and research institutions in France or abroad, or from public or private research centers.
L'archive ouverte pluridisciplinaire HAL, est destinée au dépôt et à la diffusion de documents scientifiques de niveau recherche, publiés ou non, émanant des établissements d'enseignement et de recherche français ou étrangers, des laboratoires publics ou privés. 
Ethyl silicate for unbaked earth tablets conservation: evaluation of the physico-mechanical aspects

TIENNOT Mathilde ${ }^{\mathrm{a}-\mathrm{b}-\mathrm{c}^{*}}$, MERTZ Jean-Didier ${ }^{\mathrm{b}-\mathrm{c}}$, BOURGÈS Ann ${ }^{\mathrm{b}-\mathrm{c}}$, LIÉGEY Anne ${ }^{\mathrm{d}}$, CHEMMI Atika ${ }^{\mathrm{a}-\mathrm{e}}$, BOUQUILLON Anne ${ }^{\mathrm{a}}$

${ }^{a}$ Centre de Recherche et de Restauration des Musées de France, 14 Quai Fr. Mitterrand, 75001 Paris, France

${ }^{\mathrm{b}}$ Laboratoire de Recherche des Monuments Historiques, 29 rue de Paris, 77420 Champs-surMarne, France

${ }^{\text {c }}$ Sorbonne Universités, Centre de Recherche sur la Conservation (CRC, USR 3224), Muséum national d'Histoire naturelle, Ministère de la Culture et de la Communication, CNRS ; CP21, 36 rue Geoffroy-Saint-Hilaire, 75005 Paris, France

${ }^{\mathrm{d}}$ Conservator, 12 rue J.-B. Potin, 92170 Vanves, France

e Laboratoire Matière Molle et Chimie (MMC) - CNRS : UMR7167, PSL Research University - 10 rue Vauquelin 75005 PARIS, France

Corresponding author: Mathilde Tiennot - mathilde.tiennot@gmail.com Current affiliation: Rijksmuseum - Science Department Museumstraat 1, 1071 XX Amsterdam, Netherlands 


\title{
Acknowledgments
}

This study was carried out within the framework of ARTEMIE, a project started in November 2012 and financed by the Ministère de la Culture et de la Communication through the Programme National de Recherche sur la Connaissance et le Conservation du patrimoine culturel et materiel (PNRCC).

\begin{abstract}
Preservation of cuneiform tablets made with clay minerals is an ongoing conservation issue. A treatment based on TEOS consolidation has been used since 1996 at the Louvre museum. The characterization of the tablets pointed out kaolinite, illite and smectite as the three main clay minerals constituting the objects. In this research, the physico-mechanical aspects of the treatment are investigated. The penetration depth of the TEOS solution and the gradient induced are quantified using laboratory samples. TEOS treatment preserve the macroscopic swelling and the vapour transfer properties, but modifies the clay's affinity to moisture. Elastic properties are gradually improved for all clays, but only kaolinite's strength increases significantly. The impact of TEOS treatment on the natural behaviour related to the respective structure of the clays is considered, and the amount of kaolinite required to create adequate reactions appears to be of interest for conservation matter.
\end{abstract}

Keywords: cuneiform tablets, clay minerals, TEOS consolidation treatment, interactions, physico-mechanical behaviour

\section{Introduction}

As the evidence of the first writing at the end of the $\mathrm{IV}^{\text {th }}$ millennium $\mathrm{BC}$, clay tablets are a unique testimony of mankind heritage. Most of these archaeological items were prepared with unbaked earth, natural clay minerals and fine particles. Unfortunately, due to burial for many centuries, these items had been contaminated with soluble salts 
(Organ 1961). Under different storage conditions, these salts solutions may react to relative humidity $(\mathrm{RH})$ and temperature $(\mathrm{T})$ variations and may go through the material, inducing cracks and damage in the objects (Figure 1a). To preserve the contaminated objects and allow scholars to handle and read them, and to preserve the inscribed surface, hygroscopic salts need to be removed. Desalination by immersion in water is possible if a preliminary consolidation treatment prevents the collapse of the unbaked earth tablets when immerged. An adapted protocol using ethyl silicate or tetraethyl orthosilicate (abbreviated in TEOS), described in details in Liégey et al. (2010), based on feedback from stone and earth items consolidation was proposed and has been applied on tablets in critical state of conservation since 1996.

To stabilize the earth objects, firing methods have been proposed as treatment since 1901 in museums and since the 1930s in the field (Delougaz 1933, Oddy 1993). Such baking protocol has been optimized over time and is still applied in number of museums and institutions (Thickett et al. 2002). However, baking induces irreversible chemical and mineralogical modifications and color change (Baer 1978, Oddy 1993). Nowadays, the texts need to be protected, and the study of the clayey supports is of significant interest. They contain the knowledge of the preparation techniques of raw materials, the origin of the earth used for the molded paste, and may reveal organic compounds. Most of this information is lost or irreversibly altered when a baking procedure is applied (Oddy 1993). In order to provide an alternative method more respectful of the archaeological items, a consolidation treatment using a tetraethyl orthosilicate (TEOS) product was carried out (Wheeler 2005; Liégey et al. 2010). 


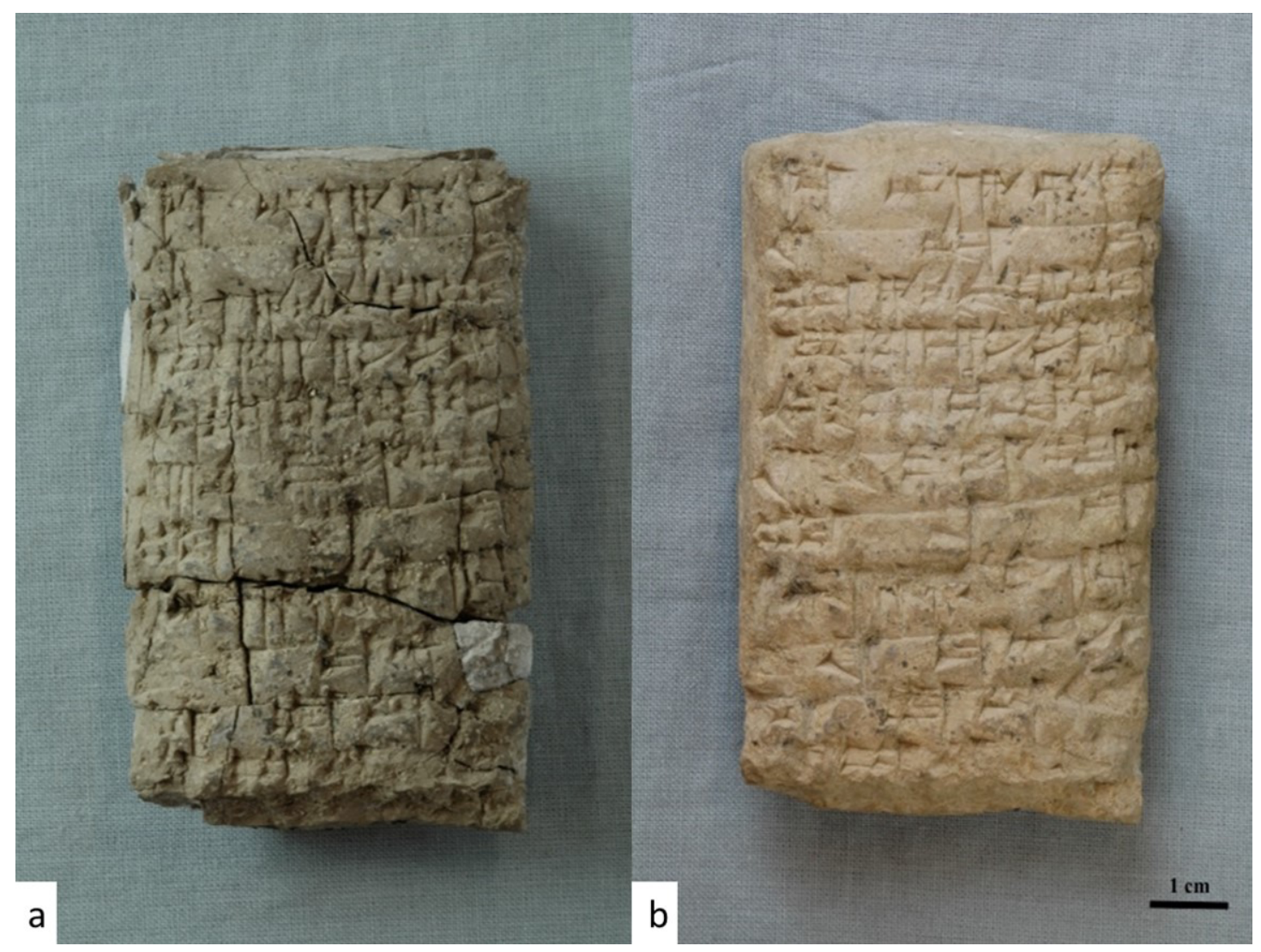

Figure 1. Cuneiform tablet AO 8578 of the Louvre museum before treatment (a) and after TEOS treatment and restoration protocol (b)

\section{TEOS as a consolidant for clay minerals}

Earthen architecture and stone conservation practice tested and discussed the use of alkoxysilanes as consolidants (Wheeler 2005, Ferron 2008). Several alkoxysilanes such as methyltrimethoxysilane (MTMOS), methyltriethoxysilane (MTEOS) and tetraethyl orthosilicate (TEOS) have been used as consolidants in the cultural heritage field (Ferron 2008, Oliver 2000, Selwitz and Oliver 2002, Coffmann 1990). Their efficiency relies on the interactions created between the various minerals, such as quartz, calcite and clays.

The reactions and interactions of the TEOS, a silicon-based compound, with materials were described in detail by Wheeler (2005). The alkoxy groups react with water 
during hydrolysis to form silanol (Si-OH), reacting itself in a condensation reaction to form siloxane bonds ( $\mathrm{Si}-\mathrm{O}-\mathrm{Si})$.

The reactions with clay minerals were discussed by Wheeler (2005). Interactions between TEOS and clays occur with the hydroxyl groups, or OH-groups, present at the surface of the minerals (Theng 1982, Sposito 1984, Wheeler 2005, Liu 2007, Qian et al. 2008). The distribution of these OH-groups on the surface of clay minerals varies with respect to their nature.

Clay minerals can be classified into two layers types depending on their arrangement of tetrahedral and octahedral sheets:

- T-O layer clay minerals are an assemblage of one tetrahedral and one octahedral sheets; kaolinite has a T-O layer structure;

- T-O-T layer clay minerals with one octahedral sheet and two tetrahedral layers (one on each side); smectite and illite are examples of such a structure.

The $\mathrm{OH}$-groups are different in distributions and accessibilities on these intrinsic layer structures. Indeed, two types of structural $\mathrm{OH}$-groups are present in kaolinite layers: the first ones at the boundaries of the octahedral and tetrahedral lattices, the second ones at the surface of the octahedral lattice of the layer (Sposito 1984). On the contrary, for T-O-T structure phyllosilicates such as illite and smectite, the hydroxyl group is rooted at the bottom in the octahedral sheet (Sposito 1984). These microstructural differences influence the reactions occurring with TEOS (Song and Sandi 2011), and have consequences on the physico-mechanical behaviour of treated clay minerals.

Previous research has underlined the various consequences when TEOS was applied on different clay minerals (Coffman et al. 1990, Fatma 1990). In the review published in 2005, Wheeler indicated that: "The clays are not all of the same structure [...]. 
These structures may have an influence on their ability to be consolidated, but how this influence occurs cannot be determined from the current stone conservation literature." Based on this statement, this research aims to study the mechanisms of the TEOS bonding with clay minerals with respect to their inherent structure. Indeed, the physico-mechanical aspects related to the consolidation of different clay types are of major interest for conservation matter.

\section{Conservation treatment on the Louvre tablets collection}

When the TEOS treatment began at the Louvre in the 1990s, the TEOS selected was the Wacker $\mathrm{OH}$ (WackerChemie AG). At that time, the composition of this product was TEOS mixed with $25 \%$ in mass in ethanol. Since a few years, this commercial product is not available anymore. The Louvre's tablets were and are still treated with a homemade solution of Silres BS OH 100 (WackerChemie AG), a pure TEOS, diluted with ethanol $25 \%$ by weight, matching the former composition of the Wacker $\mathrm{OH}$.

The complete consolidation protocol was already presented in details on Liégey et al. (2010), the only steps essential for the present paper are described below.

Since 1996, tablets have been treated with the TEOS solution, applied on both sides of the objects by dripping until saturation (Figure 2). Then, the treated items were wrapped into Melinex ${ }^{\circledR}$ foil for 3 weeks to let the hydrolysis and condensation reactions to occur.

To allow all the solvents vapour to evaporate, the tablets were then unwrapped from the Melinex ${ }^{\circledR}$, and left aside for at least 6 weeks. After all these steps, the desalination process and the restoration protocol were carried out (Figure 1b). 


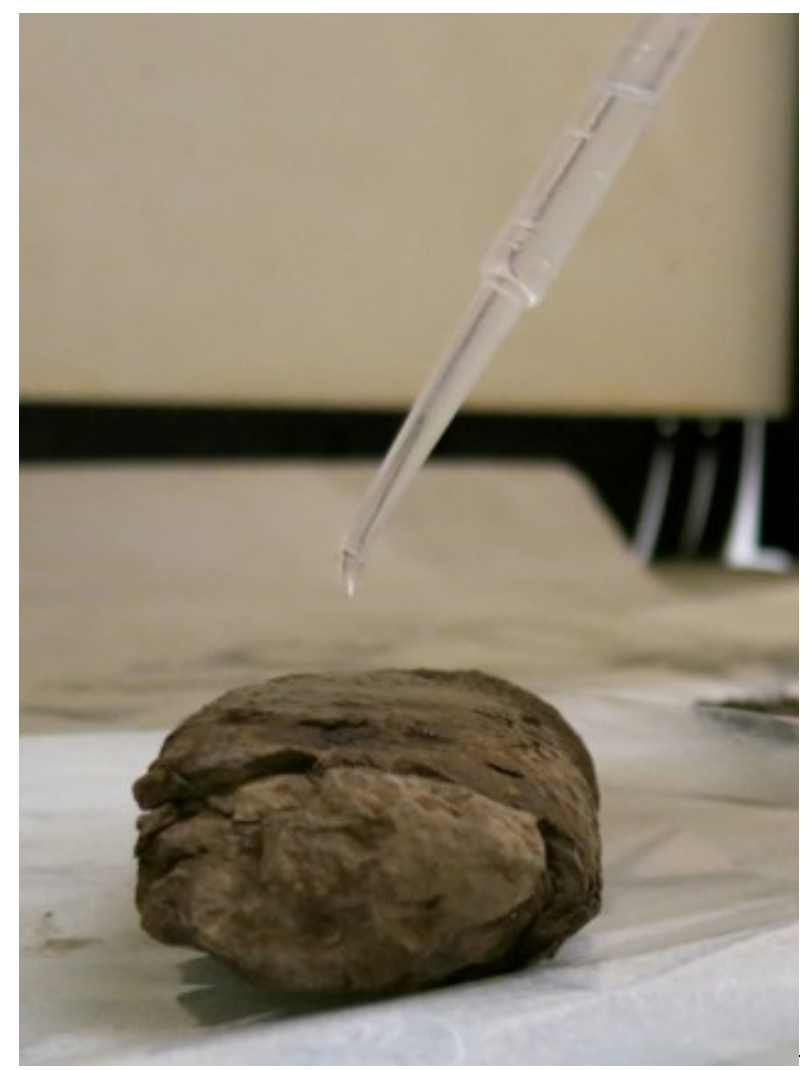

Figure 2. Consolidation solution (Silres BS OH 100 diluted in ethanol) applied on the tablet by dripping until saturation. The same protocol has been used at the Louvre since the $1990 \mathrm{~s}$

Macroscopic observations underlined that when treated clay tablets were immersed in liquid water for desalination after TEOS treatment, they did not disintegrate, suggesting that efficient interactions were created between the clay platelets and the TEOS consolidant.

To better understand the influence of the TEOS treatment on cuneiform clay tablets, physico-mechanical investigations were proposed. Some experiments of the protocol and results were presented in a previous paper (Tiennot et al. 2014). The present laboratory research further investigates the interactions between TEOS and the identified main components of the items (section below), and considers the physico- 
mechanical behaviour and affinity to moisture evolution after treatment. Several aspects are studied in this paper:

- The preparation of the laboratory samples representative of the cuneiform tablets with respect to their composition and structural properties,

- The influence of TEOS on the structural behaviour of clay samples at a macroscopic scale,

- The impact of the treatment on the textural, structural and hygromechanical properties of the three clay minerals: kaolinite, illite and smectite.

\section{Materials}

\section{Characterization of the cuneiform tablets}

Fragments of tablets from the three different Mesopotamian and Iranian sites of Tello, Larsa and Susa, collected on the Louvre collections, were analysed. Complete mineralogical, chemical and structural characterizations were presented in previous papers (Liégey et al. 2010; Tiennot et al. 2014).

The cuneiform tablets were hand molded with natural earths. Clay minerals are the main components, associated with small amounts of quartz, calcite and salts from initial raw materials and burial contamination. The extracted clay fraction $(<2 \mu \mathrm{m})$ of the assemblages was investigated and the composition amounts were determined by X-Ray Diffraction (XRD) (Tiennot et al. 2014). For the three archaeological sites, smectite is the main clay mineral detected (up to the amount of $60 \%$ to $80 \%$ ), along with kaolinite and illite, which are both present at 5 to $20 \%$ (Tiennot et al. 2014).

The microstructural properties of the tablets were studied using mercury intrusion porosimetry (MIP) according to the ASTM D4404-10 standard test method (2010). The total porosity open to mercury was measured around $20 \%$ and the average pore 
access radius at $0.05 \mu \mathrm{m}$. A macroporosity in correlation with the cracks and damage induced during burial and previous storage under non-stabilized conditions was also detected from $0.5 \mu \mathrm{m}$ to $50 \mu \mathrm{m}$. All the details were presented in Tiennot et al. (2014).

\section{Laboratory samples preparation and compaction protocol}

Thanks to these results, laboratory samples representative of the structural properties of the archaeological tablets were prepared for the present laboratory protocol. In this research, we focus on the three individual kaolinite, illite and smectite to study them separately and to identify their own specific impact on the physico-mechanical aspects of the treatment. Mixtures of the clays, representative of the composition detected on tablets, were prepared in the first phase of the project. Some preliminary results on these specimens were discussed in Tiennot et al. (2014). Further research on mixture samples is currently in progress.

The raw materials were purchased and their exact compositions were determined using PIXE analysis (Tiennot et al. 2014).

In order to perform the laboratory protocol, two sets of cylindrical samples with different sizes were molded: i) a set of small cylindrical specimens $20 \mathrm{~mm}$ in diameter and $40 \mathrm{~mm}$ long and ii) a set of larger plugs $40 \mathrm{~mm}$ in diameter and $40 \mathrm{~mm}$ long (Figure 3a).

They were both prepared using a clay paste and compacted according to the following protocol.

Atterberg limits are the water contents at specific states where the clay paste becomes either plastic $\left(\mathrm{w}_{\mathrm{p}}\right)$ or liquid $\left(\mathrm{w}_{\mathrm{l}}\right)$. The liquid and plastic state thresholds of the clay's 
preparations were measured (NF P 94-051). The optimal water content $\mathrm{w}_{\text {comp }}$ allowing an adapted shaping and release of the cylindrical samples was determined around the plastic limit $\mathrm{w}_{\mathrm{p}}$, at the specific values of $\mathrm{w}_{\mathrm{comp}}=40 \%$ for kaolinite, $45 \%$ for illite and $55 \%$ for smectite.

To match the microstructural state of the clay tablets, the paste was submitted to a compaction strength of $\sigma_{\text {comp }}=0.15 \mathrm{MPa}$ over a displacement rate of $1 \mathrm{~mm} \cdot \mathrm{min}^{-1}$ using an Instron ${ }^{\circledR}$ testing machine (Merlin 5500). After compaction and release of the molded pastes, a slow drying was fulfilled. The plugs were first placed in an enclosure with a controlled saturated atmosphere at $95 \%$ of relative humidity for four days. They then dried during four days under laboratory conditions $\left(20^{\circ} \mathrm{C}-55 \%\right.$ of $\mathrm{RH})$. A final oven drying at $35^{\circ} \mathrm{C}$ during 4 hours ensured a homogeneous curing of the samples. Such a drying protocol prevented clays specimens from an early shrinkage cracking.

These two sets were then treated with the prepared TEOS solution in two different ways.

i) Like the archaeological items, the $40 \times 40 \mathrm{~mm}$ set was treated by dripping. A total of fifty drops were applied at the upper surface of the samples in three consecutive times: 20, 20 and 10 drops of solution were respectively dropped during the first, second and third application, and a resting time was applied in between to allow a good impregnation (Liégey et al. 2010). These total 50 drops correspond to 2,5 $\mathrm{ml}$ of the prepared solution (Silres BH OH 100 diluted in ethanol). Such surface application method enables the evaluation of the potential gradient of the properties induced within the samples. 
ii) On another hand, to obtain the homogeneous treatment of the samples required for some experiments, the second set of $20 \times 40 \mathrm{~mm}$ plugs was fully immersed for less than one minute in the solution (Figure 4a). This one minute immersion induced the delamination of both illite and smectite samples (Figures $3 \mathrm{~b}$ and $4 \mathrm{c}$ ).

Finally, the same polymerization and drying protocol carried out for the tablets was applied on the two sets of laboratory samples. No colour change was noted.
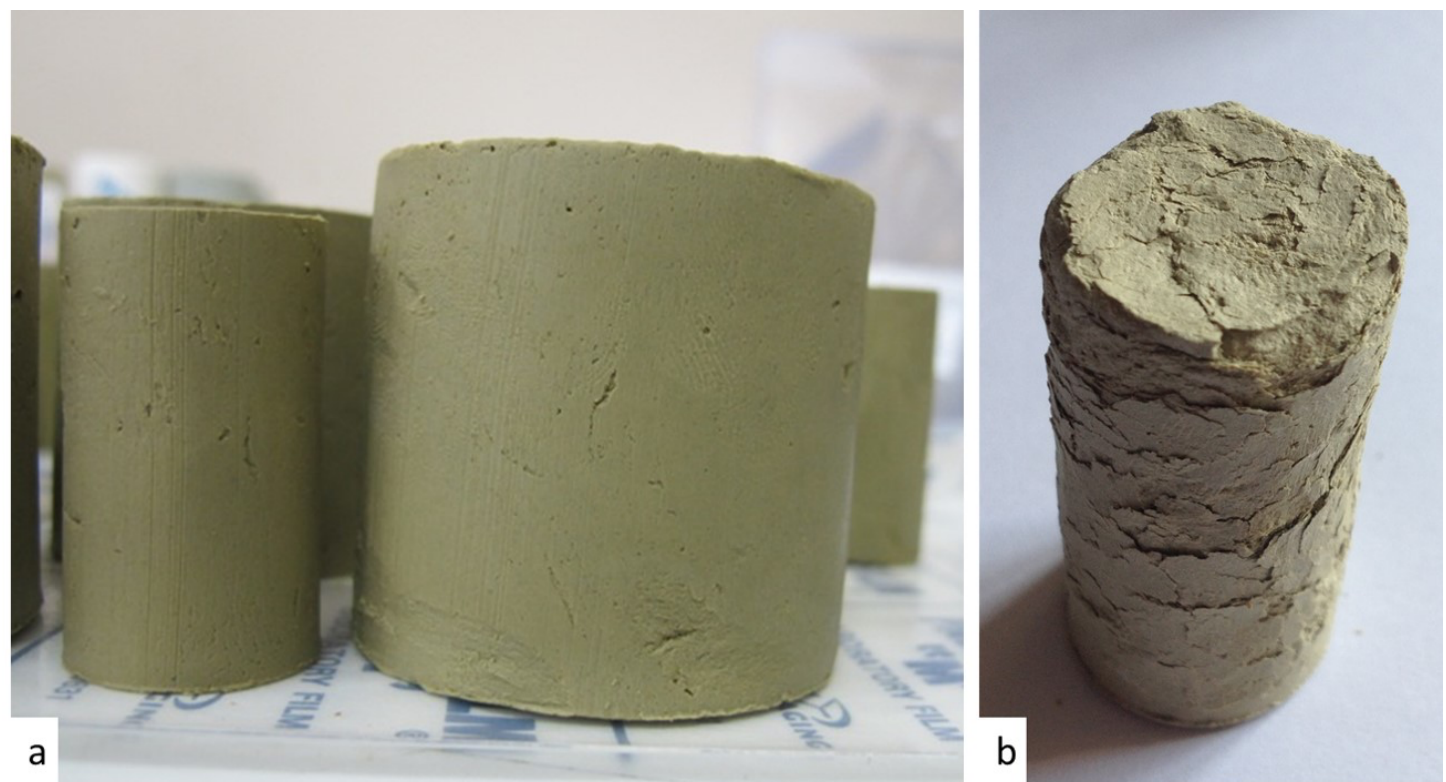

Figure 3. Samples of smectite during the preparation of the two sets (a) and illustration of the delamination at the surface of a small sample of smectite after treatment by immersion (b) 

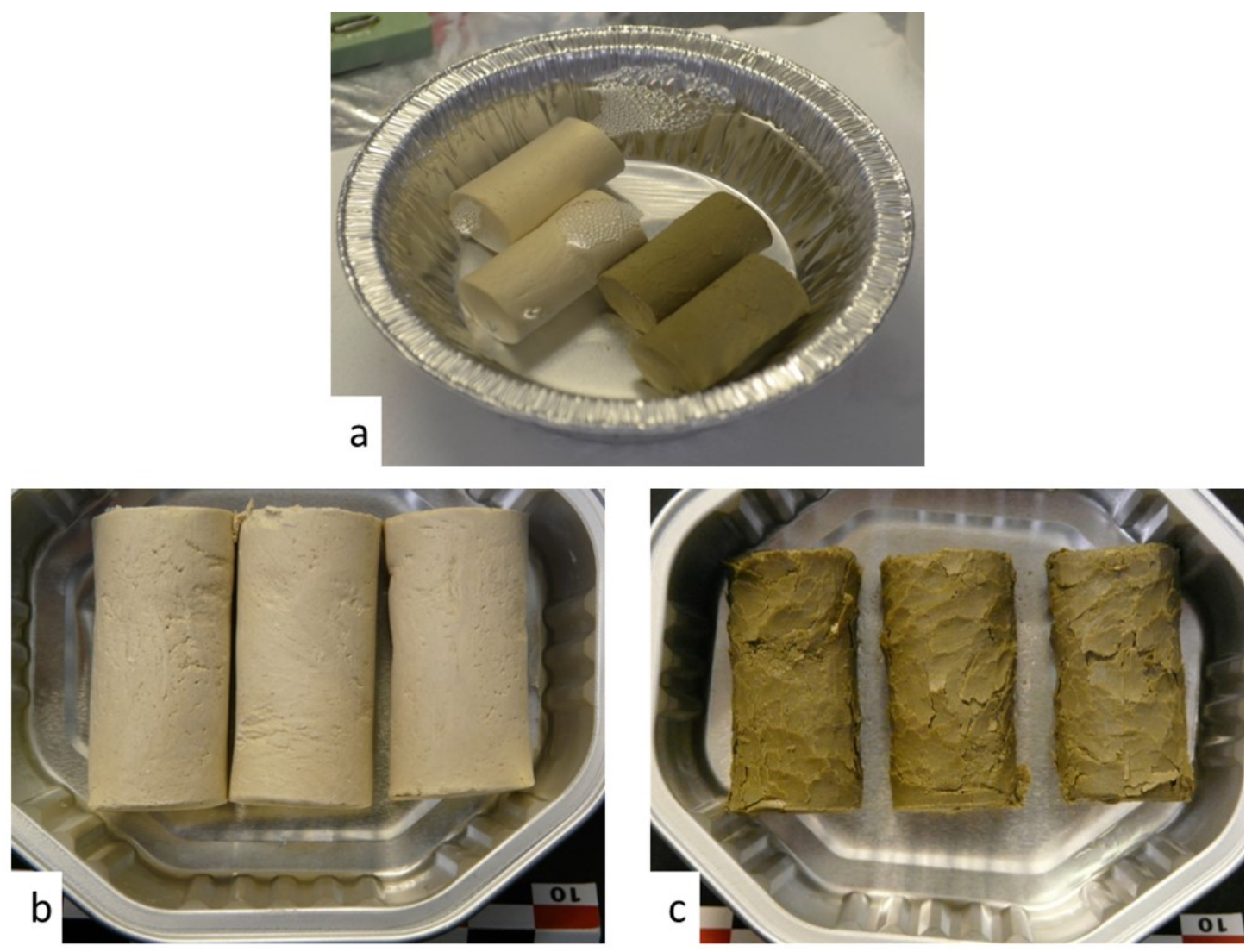

Figure 4. Small laboratory samples of kaolinite and smectite immersed in the consolidation solution during less than a minute (a), and samples of kaolinite (b) and smectite (c) after immersion

\section{Results: evaluation of the physico-mechanical behaviour}

\section{Macroscopic observations}

The application of the solution provides first information on the created interactions with the clays. Kaolinite samples are the only ones that do not suffer from surface delamination when totally immersed in ethyl silicate (Figure 4b). On the contrary, illite and smectite present delamination of their surface (Figure $3 b$ and $4 c$ ). These first observations point out differences in TEOS application consequences depending on the clay types. 


\section{Dimensional behaviour}

\section{Methodologies}

A significant property of clay-molded items is their ability to swell and shrink when subjected to variations in relative humidity. The free swelling ability of the $20 \times 40$ mm samples is monitored before and after treatment on a climatic chamber (Vötsch VCL4006). Linear Variable Differential Transformer (LVDT) sensors (TWK ${ }^{\circledR}$ technology) with $0.3 \mu \mathrm{m}$ accuracy measure the length deformation (perpendicular to the compression direction) of the clays. The samples are subjected to three successive cycles of relative humidity variations under isothermal conditions at $20^{\circ} \mathrm{C}$, where a humidification phase at $95 \%$ of $\mathrm{RH}$ is hold for 72 hours and is followed by a drying at $30 \%$ of RH phase of 48 hours.

\section{Results and discussion}

The free hygric swelling strain $\varepsilon_{\mathrm{s}}$ quantifies the ability of a material to expand and shrink upon RH variations. Higher dimensional variations indicate a higher sensitivity to moisture. Untreated kaolinite is the less sensitive clay, with $\varepsilon_{\mathrm{s}}=0.5 \mathrm{~mm} \cdot \mathrm{m}^{-1}$. Untreated illite's macroscopic dilatation is measured at $6.9 \mathrm{~mm} . \mathrm{m}^{-1}$, and smectite is the most sensitive to moisture, with a free swelling measured around $16 \mathrm{~mm} . \mathrm{m}^{-1}$ (Figure 5 and Table 1).

With the TEOS solution, the macroscopic expansion remains the same for the three clays, and is even slightly increased (Table 1). The application of the solution preserves the macroscopic shrinkage and swelling ability of the samples, and the results illustrate the reversibility of the dimensional behaviour along the several cycles of hygric solicitations. The small increase of swelling increment after TEOS treatment may be the consequence of the deposition of the product. 
Coffman et al. (1990) indicated in a previous research that a consolidation treatment should "prevent the development of a rigid, non-expandable outer skin". A significant modification of the swelling ability after treatment may induce an accelerated deterioration on the material (Coffman et al. 1990). Snethlage and Wendler (1991) mentioned that alkoxysilanes may induce unwanted dilatation increase of clay-bearing stones. Rodriguez and Costa (1996) also warned on the risks due to a potential interfacial behaviour formation, or a strong modification of the inherent properties after stones' treatment, because of the undesirable stresses that could be induced. For the present research, and based on previous studies on both stones and raw clays consolidation (Wheeler 2005), the preservation of the macroscopic swelling ability of the treated material is considered as an interesting result.

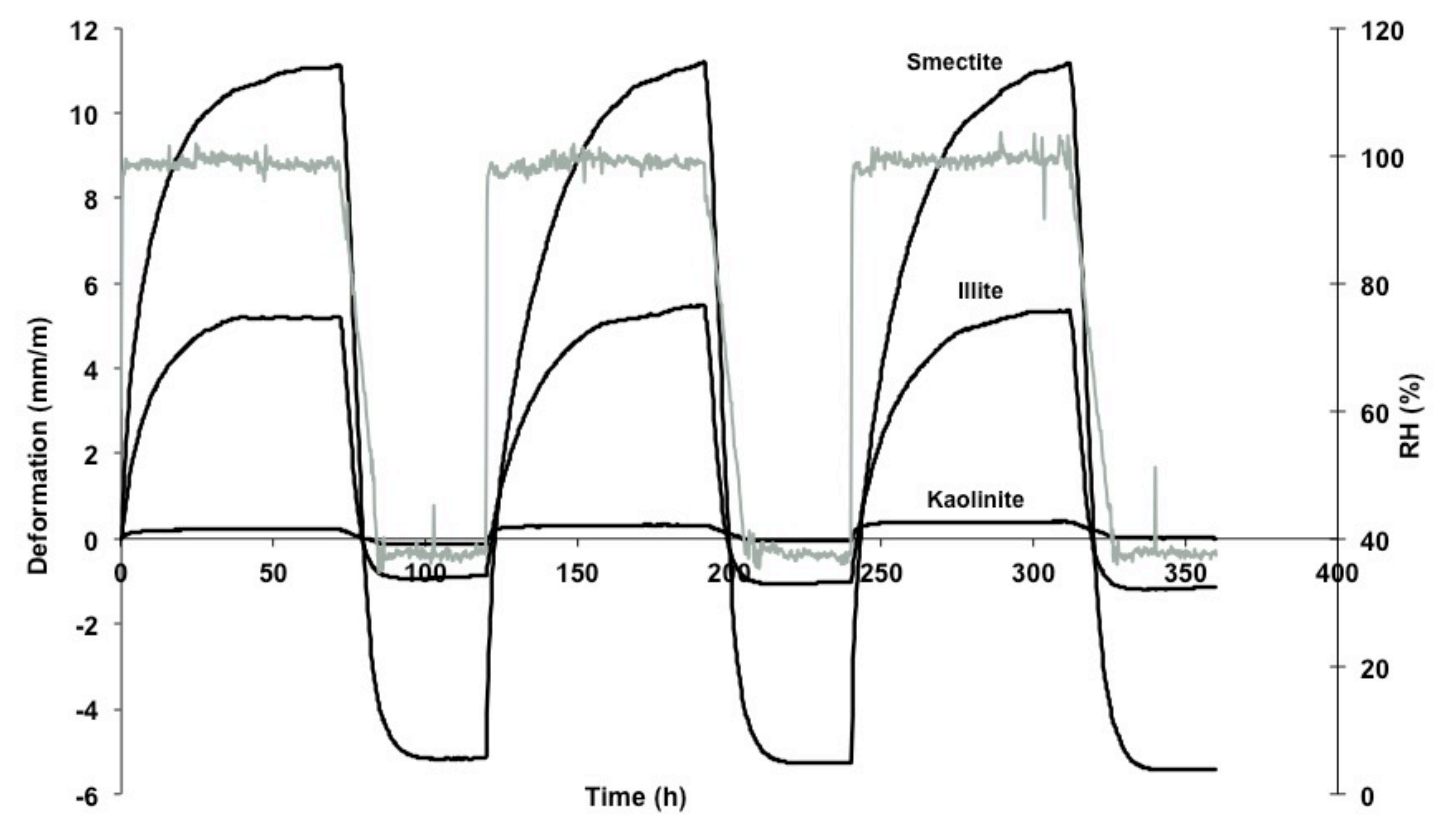

Figure 5. Dilatation of the kaolinite, illite and smectite samples before treatment during three cycles of 30-95\% variations of relative humidity (in black) and variations of the relative humidity (in grey) 


\begin{tabular}{ccccc}
\hline \multirow{2}{*}{ Hygric dilatation $\varepsilon_{\mathrm{s}}\left(\mathrm{mm} \cdot \mathrm{m}^{-1}\right)$} & & Kaolinite & Illite & Smectite \\
\cline { 2 - 5 } & Untreated & 0.5 & 6.9 & 16.0 \\
\cline { 2 - 5 } & Treated & 2.4 & 8.8 & 16.1 \\
\hline Water vapor permeability $\delta(\mathrm{kg} / \mathrm{m} . \mathrm{s} . P a)$ & Untreated & $1.19 .10^{-11}$ & $1.69 .10^{-11}$ & $1.99 .10^{-11}$ \\
\cline { 2 - 5 } & Treated & $1.39 .10^{-11}$ & $1.91 .10^{-11}$ & - \\
\hline Specific surface area $\mathrm{S}_{\mathrm{BET}}\left(\mathrm{m}^{2} \cdot \mathrm{g}^{-1}\right)$ & Untreated & 8.5 & 37.0 & 81.8 \\
\cline { 2 - 5 } & Treated & 7.2 & 31.4 & 75.1 \\
\hline Total pore volume $\mathrm{V}_{\mathrm{P}}\left(\mathrm{cm}^{3} \cdot \mathrm{g}^{-1}\right)$ & Untreated & 0.035 & 0.089 & 0.124 \\
\cline { 2 - 5 } & Treated & 0.030 & 0.084 & 0.109 \\
\hline \hline
\end{tabular}

Table 1 - Free hygric swelling strain, water vapour permeability, specific surface area and total pore volume for untreated and consolidated samples

\section{Microstructural properties and affinity to moisture}

\section{Methodologies}

The dimensional behaviour under moisture variations illustrates the clay mineral's sensitivity to moisture. Investigation of their affinity to moisture and their microstructural properties before and after treatment is also proposed in this research to better understand the interactions created with the TEOS.

Water vapour permeability $\left(\delta_{\mathrm{p}}\right.$ ) quantifies the amount of vapour naturally going through the material. Five millimetres thick discs sliced along the 40 x $40 \mathrm{~mm}$ plugs are used for water vapour permeability $\delta_{\mathrm{p}}$ measurements based on the wet cup system. This wet cup system creates a gradient of relative humidity from a sealed cup where $\mathrm{RH}=100 \%$ (moisture provided by a water tank), to the atmosphere under laboratory conditions where $\mathrm{RH}=60 \%$. The vapour passes through the slice of the material. The weight loss due to vapour transmission through the material is followed using the 
standard protocol (NF EN 15803). Measurements are only performed on samples of kaolinite and illite (details are in Tiennot et al. 2014).

Dynamic Vapour Sorption (DVS) quantifies the affinity of clay samples to retain moisture. The aim is to measure the amount of water absorbed by the samples and the dynamics of this adsorption. Analyses are performed under isothermal conditions (25 $\left.\pm 0.1^{\circ} \mathrm{C}\right)$ on small representative solid samples $(500 \mathrm{mg})$ using the water vapour sorption analyser $\operatorname{SPS}^{\circledR}$ (proUmid company) with a $10 \mu \mathrm{g}$ resolution sensor. Equilibrium moisture content determination and sorption/desorption isotherms are reached for 5 -fixed $\mathrm{RH}$ values from $0 \%$ to $90 \%$ of $\mathrm{RH}$ during a week test.

To study and quantify the affinity to moisture, nitrogen adsorption/desorption analyses are realized. The Brunauer-Emmett-Teller (BET) theory is used to quantify the specific surface area $\mathrm{S}_{\mathrm{BET}}$, or the total surface area per unit of mass, of the samples. The amount of nitrogen absorbed by the surface at different relative pressure (ranging from $\mathrm{p} / \mathrm{p}_{0}=0.05$ to 0.3 , with $\mathrm{p}$ the equilibrium pressure and $\mathrm{p}_{0}$ the saturation pressure) at $-195^{\circ} \mathrm{C}$ is measured using a BELSORP ${ }^{\circledR}$-Max system. The total pore volume $\mathrm{V}_{\mathrm{p}}$ is calculated at the chosen $\mathrm{p} / \mathrm{p}_{0}=0.98$. Samples are first prepared by outgassing at $60^{\circ} \mathrm{C}$ overnight under vacuum.

\section{Results and discussion}

For all clay types, sorption and dilatation tests confirm the penetration and condensation of ethyl silicate into the porous network. Water vapour can still percolate through the clay samples, revealing that the pore network is not totally filled by the product.

Values for reference non-treated discs of kaolinite, illite and smectite are compared with results measured on the top discs sliced from a treated core (except for smectite) 
(Table 1). Untreated kaolinite shows the lowest ability to transfer vapour, while untreated smectite has the highest permeability. After TEOS application, permeability increases up to $13 \%$ for illite and $17 \%$ for kaolinite (Table 1 ). The product still allows the free transfer within the clay samples and contributes to an improved fluid transport as an increased amount of vapour passes through.

The increase in permeability could be related to water molecules' slippage on the clay platelets. This slippage is hindered on untreated samples because of the low water adsorption phenomenon at the surface of the minerals, as described in Hammecker et al. (1992). The evolution of water vapour permeability seems also to be consistent with a clay minerals aggregate formation. The reactions occurring at the surface of the clay platelets create interactions between several particles and induce porous network reorganization due to aggregation, as suggested in previous studies (Bracho et al. 2012).

Thanks to the DVS analyses, water vapour contents of $2 \%, 9 \%$ and $14 \%$ in mass are measured respectively for kaolinite, illite and smectite before TEOS application. As expected with respect to the measured swelling ability (Figure 5), smectite shows the highest water sorption. The dynamic sorption behaviour highlights the decrease of the adsorption ability resulting from the TEOS treatment. The water sorption of illite and smectite is modified in a range of $10 \%$ loss, indicating a lower affinity to moisture after treatment (Figure 6). No significant effect is noted on kaolinite.

Adsorption and desorption analyses underline a systematic decrease of the specific surface area $\mathrm{S}_{\mathrm{BET}}$ and the total pore volume $\mathrm{V}_{\mathrm{P}}$ after treatment for all clay samples, with a higher loss for smectite (Table 1). 


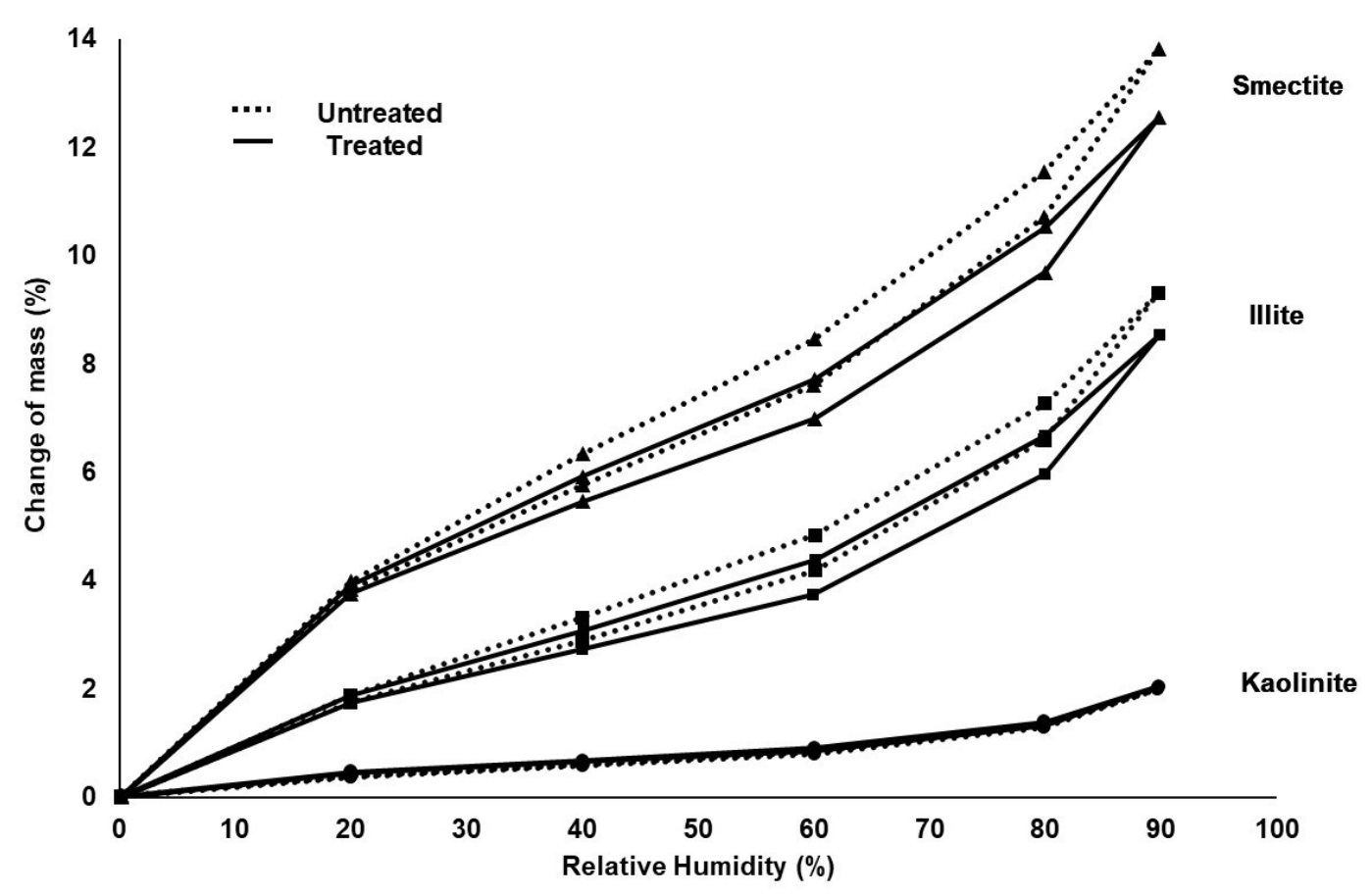

Figure 6. Change of mass (related to the lowest sample mass) with relative humidity for the three clay minerals before and after consolidation treatment measured by DVS

\section{Mechanical properties and penetration depth of the solution}

Both elastic properties and strength of the clays may be modified after TEOS treatment. Such modifications are of major interest for conservation. On this research we focus on the characterisation of two types of properties:

i) the elastic properties with the measurement of the Young's modulus E describing the ability of a material to be deformed under a stress and the reversibility of that deformation, or the elasticity of the material; and the shear modulus $\mathrm{G}$, also called rigidity modulus, describing the deformation under a shear stress.

ii) the strength of the material, which describes the ability of the sample to withstand a load; the mechanical testing we have decided to use is the 
Biaxial Flexural Strength (BFS) analysis, as described below. The Biaxial Flexural Strength (BFS) measurement is proposed because the sample required is a thin disc (Figure 7), and is a way to quantify the potential gradient induced on the mechanical behaviour.

The mechanical behaviour is also considered to evaluate the penetration depth of the solution.

\section{Slice every $5 \mathrm{~mm}$}

a
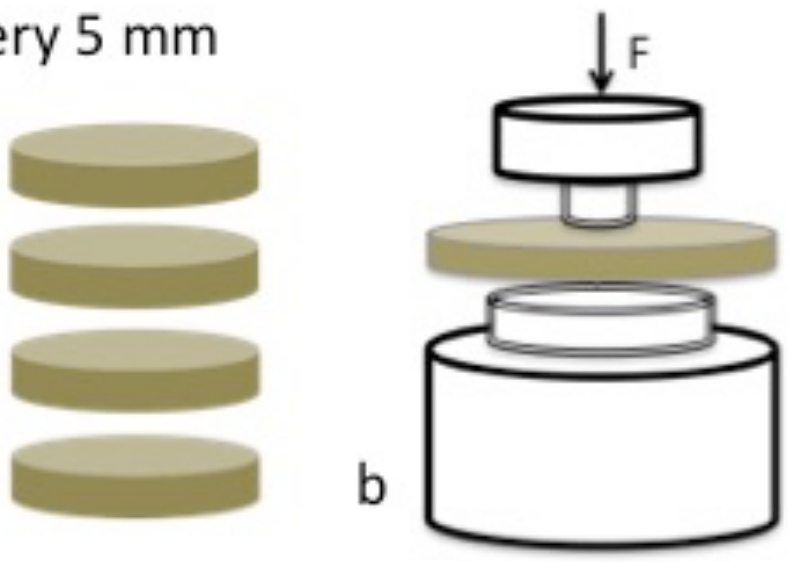

Figure 7. Slices are prepared every $5 \mathrm{~mm}$ from the consolidated surface (a) and are placed on the Biaxial Flexural Strength device (b)

\section{Elastic properties and penetration depth}

\section{Methodologies}

Elastic properties are studied using a non-destructive acoustical method, also named dynamic methods, allowing us to use the samples for further complementary analysis and adapted to be transposed and used on museum objects.

Two dynamic systems are considered in this study. First a GrindoSonic ${ }^{\circledR}$ system based on two modes resonance frequencies is used to measure the elastic properties of the $40 \times 40 \mathrm{~mm}$ plugs. A physical impact inducing an acoustic excitation under two modes, flexion and torsion, is applied on the sample with a little hammer (Siggins 1993). As pulse velocities within the material are related to its elastic constants, the 
dynamic elastic properties, Young's modulus E and shear modulus G, and Poisson's ratio $v$, are measured.

Elasticity is also related to the ultrasonic wave velocity within the material. A Ginger CEBTP AU 2000 device is used to generate a wave in the sample. Sharp tips are mounted on top of the two sensors applied on the sample diameter. As the consolidation product modifies the wave propagation, such velocity measurements along the profile allow the quantification of the gradient induced by the ethyl silicate progressive penetration, and are an indirect way to identify the penetration ability of the solution, from the surface to the bulk material. The results presented in Figure 8 are the mean values for measurements on 4 samples of kaolinite, illite and smectite.

\section{Results and discussion}

Elastic properties of untreated clay samples are measured to establish the reference values of the bulk material, and to quantify the difference between the three individual clays. Illite and smectite's samples both present similar elastic moduli, while kaolinite's samples show lower elastic Young's modulus (Table 2). These results are comparable with previous research on mechanical behaviour of T-O compared to T-O-T clay structure (Giroud and Bottero 1972).

After TEOS application, the wave propagation along the $40 \times 40 \mathrm{~mm}$ plug's profile is gradually modified for the three clays (Figure 8). Each segment - from 0 to $5 \mathrm{~mm}$, from 5 to $10 \mathrm{~mm}$, etc. - describes the average value of the Young's modulus measured for each slice and are compared with the reference average value (Figure 8). After treatment, the Young's modulus E increases and reaches almost $2000 \mathrm{MPa}$ for kaolinite, $4700 \mathrm{MPa}$ for illite and $3200 \mathrm{MPa}$ for smectite. Below $10 \mathrm{~mm}$, Young's modulus values are in the range of the properties measured for the bulk material 
before consolidation. Results on the elastic behaviour indicate that: i) the surface where the product was applied shows a strong increase in Young's modulus for the three clay minerals samples and ii) a $10 \mathrm{~mm}$ gradient of Young's modulus $\mathrm{E}$ is induced by the product penetration.

\begin{tabular}{cccc}
\hline \hline Untreated samples & Kaolinite & Illite & Smectite \\
Young Modulus E $(\mathrm{MPa})$ & $734( \pm 150)$ & $2707( \pm 904)$ & $2290( \pm 594)$ \\
Shear modulus G $(\mathrm{MPa})$ & $281( \pm 66)$ & $1152( \pm 479)$ & $970( \pm 311)$ \\
Poisson ratio $v$ & $0.31( \pm 0.1)$ & $0.18( \pm 0.1)$ & $0.20( \pm 0.1)$ \\
\cline { 2 - 4 } & & & \\
\cline { 2 - 4 } Biaxial flexural stress $\sigma_{\max }(\mathrm{MPa})$ & $0.21( \pm 0.1)$ & $1.79( \pm 0.7)$ & $1.37( \pm 0.5)$ \\
\hline \hline
\end{tabular}

Table 2. Reference mechanical properties of kaolinite, illite and smectite samples before treatment

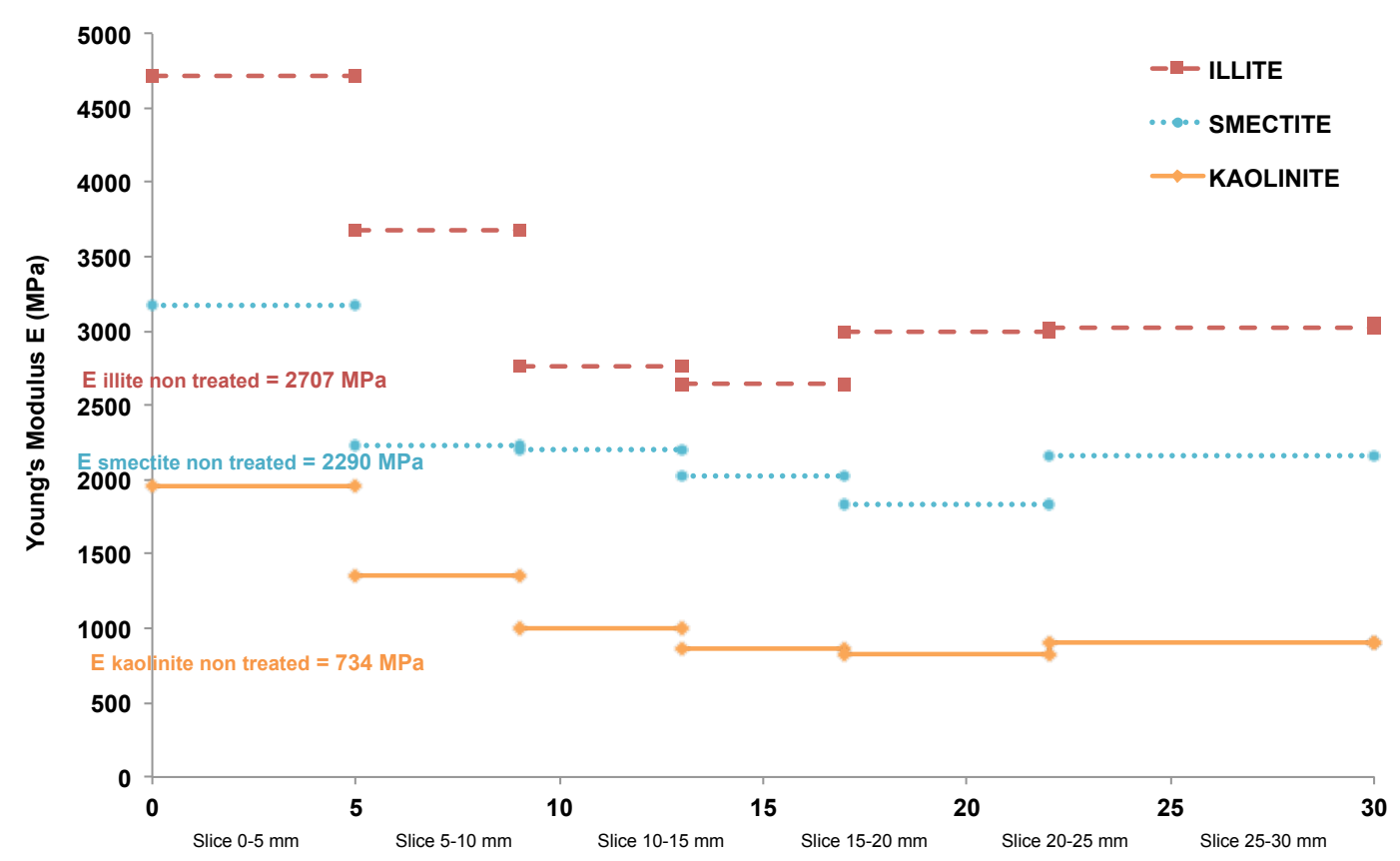

Figure 8. Elastic Young's modulus E along the consolidated profile of the kaolinite, illite and smectite samples; a segment represents the mean value for a slice: $0-5 \mathrm{~mm}$, 5-10 mm, etc. 


\section{Failure strength}

Methodologies

The disc is loaded on an Instron ${ }^{\circledR}$ testing machine (Merlin 5500) between two rings, the first fixed and the second applying the load on the sample top at a constant displacement rate of $0.2 \mathrm{~mm} \cdot \mathrm{min}^{-1}$. Reference strength $\left(\sigma_{\max }\right)$ of untreated clay discs is measured and compared to the strength of the treated slices each $5 \mathrm{~mm}$ from the surface using a diamond saw. Properties for the untreated clays are the mean values for 10 discs, while results for treated discs are obtained using 4 slices at each level (0$5 \mathrm{~mm}, 5-10 \mathrm{~mm}, 10-15 \mathrm{~mm}, 15-20 \mathrm{~mm}$ ) (Figure 9). It should be noted that superficial cracks appeared on top of all smectite plugs after treatment, therefore, no slicing of the first five millimetres was possible.

\section{Results and discussion}

The values of Biaxial Flexural Strength of untreated samples illustrate a consistent difference between the three individual clays. Reference kaolinite's samples present a lower ability to resist to a load with $\sigma_{\max }=0.21 \mathrm{MPa}$, while illite and smectite samples show a higher resistance up to $\sigma_{\max }=1.79 \mathrm{MPa}$ for illite (Table 2).

For both kaolinite and illite, the mean values for each disc -0 to $5 \mathrm{~mm}, 5$ to $10 \mathrm{~mm}$, 10 to $15 \mathrm{~mm}$ - sliced along the profile of the treated cores are superimposed with the reference values of the bulk material (standard deviations in dots) for comparison (Figure 9). Results for each disc are presented in Table 3. Only kaolinite's samples are strengthened after the application of the ethyl silicate. Resistance of illite samples is not affected. As a comparison, in their research in 1990, Coffman et al. observed the same effect, with an increase in compressive strength for kaolinite and the lack of consolidation effect on T-O-T structure clays' samples. Similar results are obtained 
here after TEOS treatment. It seems that interactions within the T-O or T-O-T clay structures induced different consequences on the mechanical behaviour of the samples and the evolution after TEOS application.

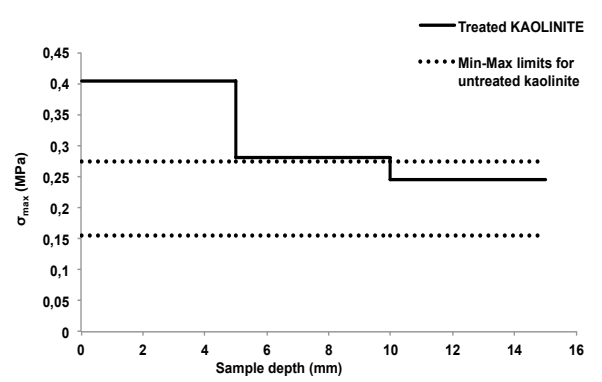

a)

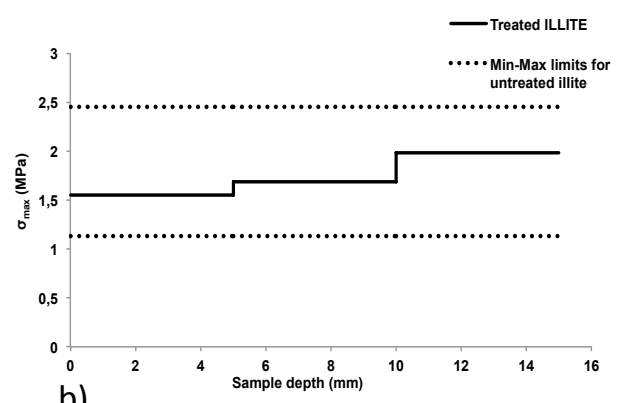

b)

Figure 9. Mechanical resistance along the consolidated sample profile (in line) compared with the values obtained for the raw clay (in dots): kaolinite (a) and illite (b)

\begin{tabular}{ccc}
\hline \hline Biaxial flexural stress $\boldsymbol{\sigma}_{\max }(\mathbf{M P a})$ & Kaolinite & Illite \\
0-5 mm slice & $0.40( \pm 0.12)$ & $1.55( \pm 0.5)$ \\
5-10 mm slice & $0.28( \pm 0.13)$ & $1.69( \pm 0.15)$ \\
10-15 mm slice & $0.24( \pm 0.04)$ & $1.13( \pm 0.08)$ \\
\hline
\end{tabular}

Table 3 - Biaxial flexural strength (BFS) of the samples of kaolinite and illite, for slices at $0-5 \mathrm{~mm}, 5-10 \mathrm{~mm}$ and $10-15 \mathrm{~mm}$, from the treated surface to the bulk material

\section{Advances for the treatment of cultural heritage items}

In practice, no microcracks, material loss nor colour change were observed on the treated clay tablets stored under controlled atmosphere at the Louvre museum after more than twenty years. With this study, several results are highlighted. The measured 
penetration depth of $10 \mathrm{~mm}$ is helpful information. It confirms that TEOS application on each side of tablets is sufficient for an effective treatment of the whole tablets, thinner than $20 \mathrm{~mm}$. With TEOS treatment, water vapour can still percolate through all clays samples. No macroscopic pore blocking is generated by the TEOS application. Thus, soluble salts solutions are more likely to pass through the bulk without microcracking during the desalination phase (process described in detail in Liégey et al. (2010)).

As a result of these first investigations, the presence of kaolinite particles may be a point of interest for further research. Even if this is not the primary aim of the TEOS application, kaolinite improves the resistance strength of the objects. Treated tablets can be handled without any damage. Moreover, because of its specific properties, there may be a threshold amount of kaolinite required for an effective treatment and to avoid delamination of the treated surface (Figure $4 \mathrm{~b}$ ). This laboratory investigation and the practical feedbacks from twenty years of tablet's consolidation without delamination effect suggest that the objects may contain kaolinite. Further studies are currently being conducted to determine if a minimum amount of kaolinite is required. First outcomes on cores molded with mixture of the three natural clays with a controlled amount of kaolinite were presented in Tiennot et al. (2014). Complete results may help to extend this consolidation protocol to other cultural heritage objects.

\section{Conclusion}

Unbaked earth tablets from the Louvre museum were studied to evaluate the TEOS consolidation treatment proposed in the 1990s. Samples of individual clay minerals, 
kaolinite, illite and smectite, were molded to investigate the impact of TEOS consolidation on their respective behaviour.

Reactions between TEOS and the OH-groups distributed at the surface of the clays preserve the swelling and vapour transfer properties, but the treatment modifies their affinity to moisture. Combined analyses illustrate that TEOS impact results less from a geometrical pore blocking than from a physico-chemical surface effect. After treatment, elastic properties are gradually improved for the three clays, while only kaolinite's strength increases significantly. Identified behaviour evolution of the individual clay minerals highlight the influence of T-O and T-O-T layer type on the physico-mechanical aspects of the treatment.

The clay phases present in the objects should be analysed in detail before the application of TEOS product, as the quantified amount of kaolinite identified may help to choose TEOS treatment or not for each specific cultural heritage object. Indeed, for conservation matters, a minimum amount of kaolinite seems to be necessary to create adequate reactions with TEOS. Further research on the amount of kaolinite required in the object is carried out.

So far, this research is a first step towards illustrating the influence of individual clay minerals and the physico-mechanical aspects related to TEOS treatment.

\section{Material list}

Silres ${ }^{\circledR}$ BS OH 100TM: Wacker

Kaolinite: Imerys

Illite and smectite: Argiletz

Melinex $^{\circledR}$ : polyester film (see Liégey et al. 2010) 


\section{References}

ASTM D4404-10: 2010. Standard Test Method for Deterioration of Pore Volume and Pore Volume Distribution of Soil and Rock by Mercury Intrusion Porosimetry, ASTM International Committee, West Conshohocken: PA 19428-2959, 7p.

Baer N.S. (1978) Chemical aspects of the conservation of archaeological materials. Advances in Chemistry.171, 25-32

Bracho D, Dougnac V, Palza H, Quijada R (2012) Functionalization of Silica Nanoparticles for Polypropylene Nanocomposite Applications. Journal of Nanomaterials

Coffman R, Selwitz C, Agnew N (1990) The Getty Adobe Research Project at Fort Selden II: A study of the interaction of chemical consolidants with adobe and adobe constituents. In 6th International Conference on Earthen Architecture : Adobe 90, New Mexico, 14-19 Oct. 1990. p. 250-254

Delgado Rodrigues Costa J (1996) Occurrence and behavior of interfaces in consolidated stones. The Conservation of Granitic Rocks, ed. J. Delgado Rodrigues and D. Costa. Lisbon: LNEC

Delougaz P (1933) The treatment of clay tablets in the field. The Oriental Institute of the University of Chicago. Studies in Ancient Oriental Civilization. Vol. 7, p. 39-57

Fatma MH (1990) Deterioration and conservation of some mud brick in Egypt, Adobe 1990, 86h international conference on the study and conservation of earthen architecture, Las Cruces, New Mexico, USA, pp277-282 
Ferron A, Matero F (2008) The consolidation of earthen surface finishes: developing a protocol for treatment evaluation at Mesa Verde National Park, 10th international conference on the study and conservation of earthen architecture, Bamako, Mali, pp. $214-221$

Giroud J-P, Bottero A (1972) Influence de propriétés physico-chimiques des argiles monominérales sur leur comportement mécanique. Bulletin de Liaison du Laboratoire des Ponts et Chaussées. 62, Réf 1204, p.105-116

Hammecker C, Esbert RM, Jeannette D (1992) Geometry modifications of porous network in carbonate rocks by ethyl silicate treatment. Proceedings of the 7 th International Congress on Deterioration and Conservation of Stone: held in Lisbon, Portugal, 15-18 June 1992 p.1053-1062

Liégey A, Bouquillon A, Recourt Ph, Bout V, André-Salvini B (2010) Les tablettes cunéiformes en terre crue du musée du Louvre. Conservation Restauration des Biens Culturels. 28, 29-36

Liu P (2007) Polymer modified clay minerals: A review. Applied Clay Science. 38, $64-76$

NF EN 15803 (2010) Conservation des biens culturels. Méthodes d'essai : Détermination de la perméabilité à la vapeur d'eau. Paris: ed. AFNOR. 14p.

NF P 94-051 (1993) Sols : reconnaissance et essais. Détermination des limites d'Atterberg. Paris: ed. AFNOR, 16p.

Oddy A (1961) 'Keep taking the tablets' or a hypochondriac's attitude to the conservation of cuneiform documents. $27^{\text {th }}$ annual meeting, Saint-Louis 
Oliver A (2000) Fort Selden adobe test wall project: Phase I, final report. Getty Research Institute, LosAngeles

Organ R.M. (1961) The conservation of cuneiform tablets. British Museum Quaterly, $23(2), 52-58$

Qian Z, Hu G, Zhang S, Yang M (2008) Preparation and characterization of montmorillonite-silica nanocomposites: A sol- gel approach to modifying clay surfaces. Physica B. 403, 3231-3238

Selwitz C, Oliver A (2002) Fort Selden adobe test wall project: Phase III, final report. Getty Research Institute, Los Angeles

Siggins, A (1993) Dynamic elastic tests for rock engineering. Comprehensive rock engineering, Principles, practice and projects, Edited by J. Hudson, Vol 3, 601-618.

Snethlage R, Wendler E (1991) Surfactants and adherent silicon resins-new protective agents for natural stone. Materials Issues in Art and Archaeology II, ed. P. Vandiver, J. Druzik, and G. Wheeler, 193-200. Pittsburgh: Materials Research Society

Song K, Sandi G (2001) Characterization of Montmorillonite Surfaces after Modification by Organosilane. Clays and Clay Minerals. 49, 119-125

Sposito G (1984) The surface chemistry of soils. Oxford University Press, New-York, $272 \mathrm{p}$.

Theng BKG (1982) Clay-polymer intercations: summary and perspectives. Clays and Clay minerals. $30,1-10$ 
Thickett D, Odlyha M, Ling D (2002) An improved firing treatment for cuneiform tablets. Studies in Conservation. 47, 1-11

Tiennot M, Liegey A, Bourgès A, Mertz J-D, Bouquillon A, Bout V, Recourt P, André-Salvini B, Monasse B, Burr A, Darque-Cerretti E (2014) Clays, unbaked earth tablets and ethyl silicate: towards an understanding of the consolidation mechanisms. ICOM-CC 17th Triennial Conference. Melbourne, Australia

Wheeler G (2005) Alkoxysilanes and the Consolidation of Stone. Los Angeles: Getty Conservation Institute, $196 \mathrm{p}$. 